\title{
Efficiency in Sugarcane Production Under Tank Irrigation Systems in Tamil Nadu, India
}

\author{
A. Nanthakumaran ${ }^{1, \#}$ and K. Palanisami ${ }^{2}$ \\ ${ }^{1}$ Dept. of Biological Science, Faculty of Applied Sciences, \\ Vavuniya Campus, Vavuniya, Sri Lanka \\ ${ }^{2}$ Director, IWMI-TATA Policy Research Program, \\ International Water Management Institute, \\ South Asia Regional Office, Hyderabad, India \\ \# Corresponding Author:
}

Tel: (94) 24324 8189; Fax: (94) 24222 2265; Email: n_ananthi@hotmail.com

\begin{abstract}
An attempt was made to study the efficiency of sugarcane production by farmers under the two different sources of water supply viz., tank water with well water and the well water only. The objective was pursued first by estimating a stochastic production frontier (SPF) using a random sample of 246 farmers under tanks with wells situation (Typology I) and 250 farmers under wells only situation (Typology II.) The results indicated that 92 percent and 93 percent of sugarcane farms are technically efficient in Typology I and Typology II, respectively. The allocative efficiency had shown that 76 percent of sugarcane farms in Typology I and 78 percent in Typology II are allocatively efficient whereas 70 percent in Typology I and 75 percent in Typology II are economically efficient in the study area. The percentages of efficiency gap in sugarcane farms in Typology I and Typology II reveals that on average sugarcane farmers in Typology II were relatively more efficient in achieving the highest technical efficiency level in the same situation where as on average sugarcane farmers in Typology I were relatively more efficient in achieving the highest economic efficiency level in the same situation. This may be because of the higher prices of inputs due to local transport cost in the Typology II when compared to Typology I. The most allocatively inefficient farmer had an efficiency gap of 31 per cent in Typology I and 43 per cent in Typology II, if improved from the current level. In Typology II, though the water supply was assured, the cost of inputs was very high when compared to Typology I, had an impact on the allocative efficiency in the Typology II.
\end{abstract}

KEYWORDS: Technical efficiency, Allocative efficiency, Economic efficiency, Tank irrigation, Sugarcane 


\section{Introduction}

The erratic rainfall pattern, declining groundwater supplies, increasing cultivation costs and inadequate labor supplies in the recent years forced the farmers to move out of the crop cultivation or sell their lands unless they improve their efficiency levels so that existing water supplies could be sufficient to irrigate the crops. As the water supply was season bound, annual crops like sugarcane faced much of the production challenges under the fluctuating water supply situation. Among the crops, sugarcane area was getting increased over years as the local sugar factories pay much attention to purchase canes upon harvest. Normally, when endowed with adequate resources, farmers used inputs in excess, expecting to reap higher yield.

The excessive cost thereby included in the production process could bring down their profit as well as the wastage of the scarce resources. Subsidized agricultural inputs could stimulate the extensive use of other compliment inputs. For instance, if irrigation water was available in plenty and at subsidized rates, farmers were tempted to use other resources like fertilizer; labor indiscriminately and inefficiently to get higher yields. In the light of this situation many studies had been done in assessing technical efficiency in rice production in all over India using different techniques. Tadesse and Krishnamoorthy (1997) examined the levels of technical efficiency across ecological zones and farm size groups in paddy farms of Tamil Nadu and found out that 90 percent of the variation of output among paddy (IR-20) farms in Tamil Nadu was due to differences in technical efficiency (TE).

Bravo-Ureta and Pinheiro (1993) justified the attention towards productivity gains arising from a more efficient use of existing technology. Bravo-Ureta and Pinheiro (1997) pointed out the importance of examining not only TE, but also Allocative Efficiency (AE) and Economic Efficiency (EE) when measuring productivity during periods of high cultivation costs. Hence, in this study an attempt was made to study the efficiency of sugarcane production by farmers, which will help address the issue of efficiency gap. The objectives of the study were: i) to assess the possibilities for productivity gain by improving the efficiency of sugarcane cultivation under different sources of water availability, ii) to suggest policy recommendation to upscale the area under sugarcane.The next chapter described the methodology adopted, study area and the sampling method. The third chapter explored the results and the discussion part and the fourth chapter contained the conclusion and recommendations based on this study.

\section{Materials and Methods}

\section{Measurement of Technical, Allocative and Economic Efficiencies}

Farrel (1957) introduced a methodology to measure economic, technical and allocative efficiency of a firm. In this methodology, economic efficiency (EE) is equal to the product of technical efficiency (TE) and Allocative Efficiency (AE). 
The TE is associated with the ability to produce on the frontier isoquant, while AE refers to the ability to produce at a given level of output using the cost-minimizing input ratios. Alternatively, Technical inefficiency is related to deviations from the frontier isoquant, and Allocative inefficiency reflects deviations from the minimum cost input ratios. Thus, EE is defined as the capacity of a firm to produce a predetermined quantity of output at minimum cost for a given level of technology (Farrel 1957; Kopp and Diewert 1982).

Stochastic Frontier Production (SFP) function was used to measure the technical efficiency of sugarcane production. The SPF can be written as

$$
Y_{j}=f\left(X_{i j}, \beta\right)+\varepsilon_{\mathrm{i}}
$$

where, $Y_{j}$ is the output of the $j^{\text {th }}$ farm, $X_{i j}$ is the $\mathrm{i}^{\text {th }}$ input used by farm $\mathrm{j}$, and $\beta$ is the vector of unknown parameters. The essential idea behind the stochastic frontier model is that $\varepsilon$ is a composed error term which is decomposed in to $V_{i}$ and $U_{i}$ where $\mathrm{V}_{\mathrm{i}}$ is a two-sided normally distributed random error term that captures the stochastic effects outside the farmer's control, measurement errors and other statistical noise. The term $U_{i}$ is a one-sided efficiency component that captures the technical inefficiency of the farmer (Aigner et al., 1977; Meeusen and Van den Broeck 1977).

\section{Specified Models Used}

The functional form for the sugarcane farm in the study area was specified as

$$
\ln Y_{i}=\beta_{0}+\beta_{1} \ln X_{1 i}+\beta_{2} \ln X_{2 i}+\beta_{3} \ln X_{3 i}+\beta_{4} \ln X_{4 i}+\left(V_{i}-U_{i}\right)
$$

The output variable $Y_{i}$ in the above equation was the output of sugarcane crop produced. The variable $X_{1}$ includes number of sets planted , $X_{2}$ represents NPK fertilizer measured in kilogram, $X_{3}$ corresponds to total quantity of surface as well as groundwater applied to the farm during the crop period in cubic meters, $X_{4}$ included family and hired labor measured in man days; $V_{i}$ and $U_{i}$ were the components of error term. $V_{i}$ captures the stochastic effects outside the farmer's control and measurement errors and $\mathrm{U}_{\mathrm{i}}$ captures the technical inefficiency of the farmers.

Following Jondrow et al. (1982), the technical efficiency estimation was given by the mean of the conditional distribution of inefficiency term $\mathrm{U}_{\mathrm{i}}$ given $\varepsilon$; and thus defined by:

$$
E\left(U_{i} / \varepsilon_{i}\right)=\sigma_{*}\left[\frac{f *\left(\varepsilon_{j} \lambda / \sigma\right)}{1-F^{*}\left(\varepsilon_{i} \lambda / \sigma\right)}-\frac{\varepsilon_{i} \lambda}{\sigma}\right]
$$


Where $\sigma_{*}{ }^{2}=\sigma_{\mathrm{u}}{ }^{2} \sigma_{v}{ }^{2} / \sigma^{2}, f^{*}$ wass the standard normal density function, and $F^{*}$ was the distribution function, both functions being evaluated at $\lambda \varepsilon / \sigma$, where $\lambda=\sigma_{u} / \sigma_{v}$, $\sigma=\sqrt{\sigma_{u}{ }^{2}+\sigma_{v}}{ }^{2}$. Consequently, by replacing $\varepsilon, \sigma$., and $\lambda$ by their estimates in equation (2) and (3), we derived the estimates for $v$ and $u$. Subtracting $v$ from both sides of equation (2) yields the SFP.

$Y^{*}=f\left(X_{i}, \beta\right)-u=Y-v$

Where $Y^{*}$ was defined as the farm's observed output adjusted for the statistical noise contained in $v$. According to Aigner et al. (1977) suggested that the maximum likelihood estimates of the parameters of the model could be obtained in terms of the parameterization $\sigma^{2}+\sigma_{v}^{2} \equiv \sigma_{s}^{2}$ and $\gamma=\sigma / \sigma_{v}$. Rather than using the nonnegative parameter $\gamma$ the parameterization of Battese and Corra (1977) who replaced $\sigma_{v}^{2}$ and $\sigma_{u}^{2}$ with $\sigma^{2}=\sigma_{u}^{2}+\sigma_{v}^{2}$ and $\gamma=\sigma_{u}^{2} / \sigma_{u}^{2}+\sigma_{v}^{2}$ was utilized. The parameter $\gamma$ must lie between 0 and 1. Technical inefficiency of an individual farm was defined as Technical inefficiency $=1-\left(\exp \left(-\mathrm{U}_{\mathrm{i}}\right)\right)=1-\left(\mathrm{Q}_{\mathrm{i}} / \mathrm{Q}_{\mathrm{i}}{ }^{*}\right)$ where $\mathrm{Q}_{\mathrm{i}}{ }^{*}$ is the maximum possible output.

Equation (4) was used to compute $X_{i}$ as well as to derive the cost frontier. The cost frontier was then used to obtain the minimum cost factor demand equations, which, in turn, became the basis for calculating the economically efficient input levels $X_{i e}$.

The stochastic frontier cost functions model for estimating farm level overall economic efficiency was specified as

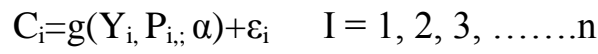

Where $C_{i}$ represented total production cost, $Y_{i}$ represented output produced, $P_{i}$, represents price of input, $\alpha$ represents the parameters of the cost function and $\varepsilon_{\mathrm{i}}$ represented the error term that was composed of two elements, that was

$\varepsilon_{\mathrm{i}}=\mathrm{V}_{\mathrm{i}}+\mathrm{U}_{\mathrm{i}}$

Here $\mathrm{V}_{\mathrm{i}}$ was a two-sided normally distributed random error term that captured the stochastic effects outside the farmer's control, measurement errors and other statistical noise. The term $U_{i}$ was a one-sided efficiency component that captured the technical inefficiency of the farmer. A Cobb-Douglas cost frontier function for sugarcane farmers in the study area was specified as:

$\operatorname{lnCi}=\alpha_{0}+\alpha_{1} \ln \mathrm{P}_{1 \mathrm{i}}+\alpha_{2} \ln \mathrm{P}_{2 \mathrm{i}}+\alpha_{3} \ln \mathrm{P}_{3 \mathrm{i}}+\alpha_{4} \ln \mathrm{P}_{4 \mathrm{i}}+\alpha 5 \ln \mathrm{Y}^{*}+\mathrm{V}_{\mathrm{i}}+\mathrm{U}_{\mathrm{i}}$ 
where $\mathrm{C}$ was the cost of production per farm measured in rupees ( $\mathrm{Rs}) ; \mathrm{P}_{1}$ was average price of sets in rupees; $\mathrm{P}_{2}$ was the average price of NPK fertilizer in rupees; $\mathrm{P}_{3}$ was the average value of water in rupees; $\mathrm{P}_{4}$ was the average daily wages of human labour in rupees and $\mathrm{Y}^{*}$ was the value of output. The $\alpha$ and $\sigma$ were parameters to be estimated.

The farm specific Economic Efficiency (EE) was defined as the ratio of minimum observed total production cost $\left(\mathrm{C}^{*}\right)$ to actual total production cost $(\mathrm{C})$ using the result of the equation (3) above. That is:

$\mathrm{EE}=\frac{C^{*}}{C}=\frac{E\left(C_{i} / u_{i}=0, Y_{i}, P_{i}\right)}{E\left(C i / u i, Y_{i} P_{i}\right)}=E\left[\exp \left(U_{i} / \varepsilon\right]\right.$

Here EE takes values between 0 and 1 .

A measure of farm specific allocation efficiency (AE) was obtained from technical and economic efficiencies estimated as

$\mathrm{AE}=\mathrm{EE} / \mathrm{TE}$

The frontier functions (production and cost) were estimated through maximum likelihood methods. For the estimation, the computer program FRONTIER version 4.1c was used.

\section{Study Area and Sample}

Two districts were purposively selected in Tamil Nadu, wherein Sivagangai districts from southern part of Tamil Nadu represent the Tank with wells situation (Typology I) and Coimbatore district from Western part of Tamil Nadu represents Wells only situation (Typology II). Tanks were the main source of irrigation in southern districts, i.e., Sivagangai.

Ten tanks in each selected district were randomly selected for the study using the list of tanks in the districts. Then 25 households in each selected tank were randomly selected for this study using the list of farmers available with the village administrative offices. Thus, the sample for this study consists of 20 tanks and 500 households which represent adequate distribution of sample households among the selected tanks. The 20 tanks selected were categorized into two different typologies based on the farm households depending upon the source of water supplies, viz., Tank with wells (Typology I) and Wells only (Typology II).

Typology I included farm households who irrigated the crop using water from the tanks and from the wells found in the tank command area as supplementary irrigation whereas the Typology II included farm households who irrigated the crop 
using water from the wells found in the tank command area where the tanks function as percolation ponds. Four households in the Typology I were excluded from the analysis because these households could not fit into this typology due to the usage of only the tank water.

Finally 246 households from Typology I and 250 households from Typology II were taken as the sample households for this study. The field data from the sample respondents relating to agriculture year 2006-07 were collected with the help of pretested interview schedule through personal interview.

Field visits were made during the crop periods for observing the water use as well as taking water measurements using marked sticks representing the depth. The sticks were used in different fields in different crop periods and depth and number of irrigations were noted. The information regarding source of irrigation for paddy lands, number of tank and well irrigations, annual pumping hours, amount of inputs used were obtained from sample respondents.

\section{Results and Discussion}

Table 1: Estimates of stochastic frontier model for sugarcane farms in Typology I

\begin{tabular}{lccc}
\hline \multicolumn{1}{c}{ Variables } & $\begin{array}{c}\text { Mean } \\
\text { (Std. Dev) }\end{array}$ & $\begin{array}{c}\text { OLS } \\
\text { Estimates } \\
\text { (Std. Error) }\end{array}$ & $\begin{array}{c}\text { ML Estimates } \\
\text { (Asymp. Std. } \\
\text { Error) }\end{array}$ \\
\hline Intercept & & $4.057^{* * *}$ & $\begin{array}{c}4.576^{* * *} \\
(0.459)\end{array}$ \\
Seed rate $\left(\mathrm{X}_{1}\right)$ in no. of sets/ha & 74,905 & $0.211^{* *}$ & $0.173^{* *}$ \\
& $(52,335.07)$ & $(0.074)$ & $(0.069)$ \\
NPK Fertilizer $\left(\mathrm{X}_{2}\right)$ in Kg/ha & 245 & $0.519^{* *}$ & $0.574^{* *}$ \\
& $(416.22)$ & $(.193)$ & $(0.188)$ \\
Water $\left(\mathrm{X}_{3}\right)$ in $\mathrm{M}^{3} / \mathrm{ha}$ & 13456 & $0.070^{*}$ & $0.047^{* *}$ \\
& $(6,480.71)$ & $(0.03)$ & $(0.018)$ \\
Labor $\left(\mathrm{X}_{4}\right)$ in man days/ha & 144 & $0.202^{*}$ & $0.210^{*}$ \\
Sigma-squared & $(91.49)$ & $(0.902)$ & $(0.851)$ \\
& & & $0.013 * *$ \\
Gamma & & & $(0.003)$ \\
Log likelihood & & & $0.86^{* * *}$ \\
\hline
\end{tabular}

***,**,* indicate significance at 1,5 and 10 per cent level respectively

The estimates of the parameters of the stochastic frontier production model revealed that all the estimated coefficients of the variables of the production function were 
positive and significant at $1 \%, 5 \%$ and $10 \%$ level of significance in both typologies (Tables 1 and 2). The positive coefficients of seed material, NPK fertilizer, water and human labor implies that as each of these variables is increased, the output of sugarcane also increases. 
Table 2: Estimates of stochastic frontier model for sugarcane farms in Typology II

\begin{tabular}{lccc}
\hline \multicolumn{1}{c}{ Variables } & $\begin{array}{c}\text { Mean } \\
\text { (Std. Dev) }\end{array}$ & $\begin{array}{c}\text { OLS } \\
\text { Estimates } \\
\text { (Std. Error) }\end{array}$ & $\begin{array}{c}\text { ML Estimates } \\
\text { (Asymp. Std. } \\
\text { Error) }\end{array}$ \\
\hline Intercept & & $2.548^{* *}$ & $2.615^{* *}$ \\
& & $(0.653)$ & $(0.637)$ \\
Seed rate $\left(\mathrm{X}_{1}\right)$ in no. of sets/ha & 71,775 & $0.119^{*}$ & $0.122^{*}$ \\
NPK Fertilizer $\left(\mathrm{X}_{2}\right)$ in Kg/ha & $(47894.45)$ & $(0.059)$ & $(0.058)$ \\
& 237 & 0.091 & $0.095^{*}$ \\
Water $\left(\mathrm{X}_{3}\right)$ in $\mathrm{M}^{3} / \mathrm{ha}$ & $(223.67)$ & $(0.052)$ & $(0.051)$ \\
& 14,225 & $0.650^{* * *}$ & $0.642^{* * *}$ \\
Labor $\left(\mathrm{X}_{4}\right)$ in man days/ha & $(6,504.84)$ & $(.117)$ & $(0.112)$ \\
Sigma-squared & 196 & $0.144 *$ & $0.138^{*}$ \\
& $(135.56)$ & $(0.078)$ & $(0.071)$ \\
Gamma & & & 0.029 \\
Log likelihood & & & $(0.018)$ \\
***** indicates significance at one and five per cent level & 0.28 \\
\end{tabular}

\section{The Cost Frontier}

The dual cost frontier for sugarcane farmers in Typology I and Typology II are derived analytically from the respective stochastic frontier production functions and given respectively by the following equations:

$$
\begin{aligned}
& \ln \mathrm{Ci}^{*}=-3.4501+0.1721 \ln \mathrm{P} 1+0.5717 \ln \mathrm{P} 2+0.0467 \ln \mathrm{P} 3+0.2095 \ln \mathrm{P} 4+0.9871 \ln \mathrm{Yi}^{*} \\
& \operatorname{lnCi} \mathrm{i}^{*}=-1.5638+0.1287 \ln \mathrm{P} 1+0.1229 \ln \mathrm{P} 2+0.6031 \ln \mathrm{P} 3+0.1358 \ln \mathrm{P} 4+0.9807 \ln \mathrm{Yi}^{*}
\end{aligned}
$$

where $C_{i} *$ is the minimum cost of production per farm of the $\mathrm{i}^{\text {th }}$ farmer in rupees (Rs).; $P_{l}$ is average price of sets in Rs. per ha; $P_{2}$ average price of NPK fertilizer in Rs. per kilogram; $P_{3}$ is the average value of water in Rs. per cubic meter; $P_{4}$ is the average daily wage rate of human labor in Rs. and $Y_{i}^{*}$ is the value of farm output measured in Rs. adjusted for any statistical noise and scale effects.

\section{Efficiency Estimates}

The technical efficiency (TE) analysis revealed that technical inefficiency affected sugarcane production in different typologies negatively as confirmed by these respective gamma values. The gamma $(\gamma)$ ratio indicated the relative magnitude of the variance $\sigma^{2}$ associated with technical inefficiency effects. Hence, in Typology I, the $\gamma$ value of 0.86 (Table 1) indicated that 86 per cent of the total variation in farm 
output was due to the differences in their technical efficiencies and it was significant at one per cent level.

The $\gamma$ value of 0.28 (Table 2) indicated that only 28 per cent of the total variation in farm output was due to differences in the technical efficiencies in sugarcane production in Typology II. But it was not statistically significant. In Typology II, farm households irrigated their crops using wells and the assured well water supply would reduce the risk of water supply.

The deciles range of percentage frequency distribution of sugarcane farmers with their efficiency levels in different typologies was given in Tables 3. This table shows that in both typologies, the farmers attained higher technical efficiency and lower AE which resulted in lower EE. This may be because of the varying price of inputs due to local transport. It was important to point out that despite the role that higher efficiency levels could have on output, productivity gains stemming from technological innovations remain of critical importance in agriculture in the study area.

Table 3: Deciles range of percentage distribution (Typology I and II)

\begin{tabular}{ccccccc}
\hline $\begin{array}{c}\text { Efficiency Level } \\
(\%)\end{array}$ & \multicolumn{2}{c}{ TE (\%) } & \multicolumn{2}{c}{ AE (\%) } & \multicolumn{2}{c}{ EE (\%) } \\
\cline { 2 - 7 } & T I & T II & T I & T II & T I & T II \\
\hline$>=90$ & 82 & 96 & 0 & 1 & 0 & 1 \\
$\mathbf{8 0 ~ - ~ 8 9}$ & 13 & 4 & 8 & 0 & 0 & 0 \\
$\mathbf{7 0 ~ - ~ 7 9}$ & 5 & 0 & 83 & 76 & 69 & 68 \\
$\mathbf{6 0}-\mathbf{6 9}$ & 0 & 0 & 8 & 14 & 22 & 15 \\
$\mathbf{5 0}-\mathbf{5 9}$ & 0 & 0 & 1 & 9 & 8 & 16 \\
Mean (\%) & 92 & 93 & 76 & 78 & 70 & 75 \\
Minimum (\%) & 72 & 85 & 56 & 55 & 52 & 54 \\
Maximum (\%) & 98 & 96 & 81 & 96 & 77 & 92 \\
\hline
\end{tabular}

Percentage (\%): The percentage (rounded) of total farms

The sample frequency distribution of sugarcane farmers in Typology I indicated a clustering of technical efficiencies in the region of greater than 90 per cent efficiency ranges, representing 82 percent of the respondents (Table 3). This implied that the farmers were fairly efficient in deriving maximum output from input, given the available resources in Typology $\mathrm{I}$.

The sample frequency distribution of sugarcane farmers in Typology II indicated that 96 percent of the respondents are with more than 90 percent TE (Table 3). This 
implied that the farmers were efficient in deriving maximum output from input with the given available resources in Typology II.

The TE ranged between 72 percent and 98 percent with the average of 92 percent in Typology I (Table 3). This means that if the average farmer in the sample was to achieve the TE level of its most efficient counterpart, then the average farmer could realize a six per cent efficiency gap (i.e., 1-(92/98) *100) and the most technically inefficient farmer revealed the efficiency gap of 27 percent (i.e., 1-(72/98))*100) . The TE ranges from 85 per cent to 96 percent with the average of 93 percent in Typology II, (Table 3). If the average farmer in the sample was to achieve the TE level of its most efficient counterpart, then the average farmer could realize a three per cent efficiency gap (i.e., 1- (93/96) $* 100)$ and the most technically inefficient farmer reveals the efficiency gap of 11 per cent (i.e., 1-(85/96))*100).

The percentages of efficiency gap in sugarcane farms in Typology I and Typology II reveals that the average and inefficient sugarcane farmers in Typology II were relatively more efficient in achieving the highest technical efficiency level in the same situation. About 69 percent of the farmers of sugarcane farms in Typology I and Typology II had the economic efficiency of 70 percent and above (Table 3) which was an indication that the sample farmers were fairly efficient. That is, the farmers were fairly efficient in producing a pre-determined quantity of sugarcane at a minimum cost for a given level of technology.

The economic efficiency of sample sugarcane farmers in Typology I ranged between 52 percent and 77 percent with the mean EE of 70 percent (Table 3). If the average farmer in the sample were to reach the EE level of its most efficient counterpart, then the average farmer could experience a efficiency gap of nine per cent (i.e., 1-(70/77))*100) and for the most economically inefficient farmer suggests an efficiency gap of 32 percent (i.e., 1-52/77))*100). In the Typology II, the mean EE was of 75 percent with a low of 54 percent and a high of 92 percent. If the average farmer in the sample were to achieve the EE level of its most efficient counterpart, then the average farmer could experience a efficiency gap of 18 percent (i.e., 1-(75/92) $* 100)$ and for the most economically inefficient farmer suggested a gap of 41 percent (i.e., 1-54/92))*100), if improved from the current level.

The percentages of efficiency gap in sugarcane farms in Typology I and Typology II revealed that the average and inefficient sugarcane farmers in Typology I were relatively more efficient in achieving the highest economic efficiency level in the same situation. This may be because of the higher prices of inputs due to higher local transport cost in the Typology II when compared to Typology I.

About 91 percent of the sugarcane farmers had the allocative efficiency of 70 per cent and above (Table 3), which was an indication that the sample farmers were fairly efficient in Typology I. That is, the farmers were fairly efficient in producing sugarcane at a given level of output using the cost minimizing input ratio. In 
Typology II (Table 3), 77 percent of the farmers have the AE of 70 per cent and above, which was an indication that the sample farmers were moderately efficient in producing sugarcane at a given level of output using the cost minimizing input ratio. The allocative efficiency of sample sugarcane farmers in Typology I range between 56 percent and 81 percent with the mean AE of 76 percent (Table 3). If the average farmer in the sample were to achieve the AE level of its most efficient counterpart, then the average farmer could experience an efficiency gap of six percent (i.e., 1$\left.(76 / 81))^{*} 100\right)$ and for the most allocatively inefficient farmer suggested a gap of 31 percent (i.e., 1-56/81))*100). For sugarcane farmers in the Typology II, the mean $\mathrm{AE}$ was of 78 percent with a low of 55 per cent and a high of 96 percent. If the average farmer in the sample were to achieve the AE level of its most efficient counterpart, then the average farmer could experience an efficiency gap of 18 per cent (i.e., 1-(78/96) $\left.)^{*} 100\right)$ and for the most allocatively inefficient farmer suggested a gap of 43 percent (i.e., 1-55/96))*100), if improved from the current level.

The mean AE of farms in the Typology II was 78 percent. Though the water supply was assured, the cost of inputs was very high when compared to other typology. The average wage rate of labor in the Typology II was Rs. 175 per day and the same costs Rs. 85 per day in the Typology I. This had an impact on the allocative efficiency in the Typology II.

\section{Conclusions and Policy Implications}

Efficiency measurement of sugarcane farms explained the farmers' performance under tank irrigation in southern Tamil Nadu. Farmers were technically efficient with more than 90 percent in both typologies but AE in Typology I was only 76 percent and Typology II was 78 percent. Due to the influence of AE, the EE level attained 70 percent in sugarcane farms in Typology I whereas it was 75 percent in Typology II.

The percentage of efficiency gap in sugarcane farms in Typology I and Typology II revealed that the average and inefficient sugarcane farmers in Typology II were relatively more efficient in achieving the highest TE level in the same situation. But as far as Economic and allocative efficiency were concerned the percentage of efficiency gaps in sugarcane farms in Typology I and Typology II revealed that the average and inefficient sugarcane farms in Typology I were relatively more efficient in achieving the highest level of economic and allocative efficiency.

It is recommended that any institutional arrangement ensuring supply of inputs to meet the quantity demanded at reasonable price could help in raising the allocative efficiency of the sugarcane farms in typology II. Also it is important that the farmers in the Typology I should be encouraged to develop water markets that will help distribute the available well water among all the farmers. It is also 
recommended that the farmers in Typology I could improve productivity gain by introducing wells in the tank irrigation system up to the threshold level. 


\section{References}

Aigner, D. J., C. A. K Lovell and P. Schmidt (1977). "Formulation and estimation of stochastic frontier production function models" Journal of Econometrics, 6(1): 21-37.

Battese, G. E. and G. S. Corra (1977). "Estimation of a production frontier model: with application to the pastoral zone of Eastern Australia" Australian Journal of Agricultural Economics, 21: 169 -179.

Bravo-Ureta, B. E, and A. E. Pinheiro (1997). "Technical, economic and allocative efficiency in peasant farming: evidence from the Dominican Republic", The Developing Economics, XXXV-1: 48-67.

Brevo-Ureta, B E. and A. E. Pinheiro (1993). "Efficiency analysis of developing country agriculture: a review of the frontier function literature" Agricultural and Resource Economic Review, 22(1): 88-01.

Farrel, M. J. (1957). "The measurement of productive efficiency" Journal of Royal Statistical Society, Series (A) 120(1): 253-260.

Jondrow, J., C. A. K. Lovell, V. Materov and P. Schmidt (1982) "On the estimation of technical efficiency in the stochastic frontier production function model" Journal of Econometrics, 19(2): 233-238.

Kopp, R. J. and W. E. Diewert (1982). "The decomposition of frontier cost functions deviations into measures of technical and allocative efficiency" Journal of Econometrics, 19(2): 319-331.

Meeusen, W. and J. van den Broeck (1977). "Efficiency estimation from Cobb-Douglas production function with composed error" International Economic Review, 18(2): 435-44.

Tadesse, B. and S. Krishnamoorthy (1997). "Technical efficiency in paddy farms in Tamil Nadu: an analysis based on the farm size and ecological zone" Agricultural Economics, 16: 185-192. 